\title{
Advanced Material Selection Technique For High Strength and Lightweight Spur Gear Design
}

\author{
Hulusi Delibaş ${ }^{1 *}$, Çağrı Uzay², and Necolet Geren³ \\ 'Adana Science and Technology University, Turkey; hdelibas@adanabtu.edu.tr \\ ${ }^{2}$ Çukurova University, Turkey; cuzay46@gmail.com \\ ${ }_{3}^{3}$ Çukurova University, Turkey; gerendr@cu.edu.tr
}

\begin{abstract}
This study aims to select optimum materials for particular spur gear designs. An advanced material selection technique called Ashby's method was used to determine suitable materials according to their material index. The method requires objective function, constraint and free variables. Objective function was set to minimizing mass based on the bending strength whereas the bending fatigue failure criteria is the constraint. All the input parameters and modification factors during the design process were taken as free variables. The suitable materials were ranked according to their index value then subjected to gear designs. A number of gear designs were performed with different types of materials to show the differences between weights of the parts. Module and face width results were also compared between each other. Lightweight and high strength materials suitable for spur gear designs were found out. And up to $63 \%$ weight reduction was achieved compared to conventional gear materials.
\end{abstract}

Keywords: Lightweight design, optimization, the Ashby method, spur gear design.

\section{INTRODUCTION}

Gears are defined as toothed members transmitting rotary motion from one shaft to another shaft. They are commonly used in all type of applications where power transfer is required such as automobiles, industrial equipment, airplanes, helicopters, and marine vessels [1]. A spur gear has teeth on the outside of a cylinder which are parallel to the axis of the cylinder. Although this is the simplest type of gears, the most commonly used type is spur gear [2]. The design of spur gears depends on input parameters such as power, speed, operating conditions, fatigue life, and require iterative process.

Gears are designed based on either bending fatigue failure or surface contact fatigue failure criteria. Many researchers have still carried out studies to determine the gear stresses called as bending stress and surface contact stress by making tooth profile modifications [3-5], using computer aided engineering tools [6-8]. Most of the researches are related to finite element analysis of the gears to verify the analytical solutions [9-11]. But the optimization related studies are still weak. Marjanovic et al. [12] developed software using $\mathrm{C}++$ code to optimize the volume of the gear trains based on selection matrix, selection of optimal materials, optimal gear ratio and optimal positions of shaft axes. Golabi et al. [13] investigated the general form of objective function and design constraints for the volume/weight of a gearbox by choosing different values for the input power, gear ratio and hardness of gears. But the material selections were made from a very narrow perspective.

A wide variety of steels, cast irons, bronzes, and phenolic resins can be a candidate for gears. In addition, new materials such as nylon, titanium, and sintered iron can also be selected [14]. And day by day, new engineering materials are introduced by suppliers for the industry. Now, the number of materials available to engineers is vast: 160,000 or more [15]. How, then, do engineers choose, from this vast menu, the material best suited to their purpose? For this reason, an advanced material selection technique must be used before starting a particular design process. A methodology suggested by Ashby [15] is an advanced material selection technique provides material charts to obtain optimum material for desired objective functions such as maximizing stiffness or minimizing mass. If the methodology properly applied, it gives guidance and certainly simplifies the initial survey for potential candidate materials. The methods lend themselves readily to implementation as computer-based tools; one, the CES Edu materials selection platform. The Ashby methodology covers all of the material properties such as mechanical, physical, optical, thermal properties [15]. On the other hand CES Selector [16] is a strong tool for material selection since it can rank the materials according to their material index or indices value which can be determined with the aid of the Ashby method. Indices that include shape provide a tool 
for optimizing the co-selection of material considering tooth shape.

Performance does not depend on just one property. Almost always it is a combination of properties that matter: For instance, the need for strength at low weight. Material properties limit performance. Lightweight designs of machine members are gaining a particular importance especially for moving vehicles, portable machinery and for aeronautics. This paper investigates lightweight materials for the particular gear designs by using the Ashby's method. A parametric study was carried out by determining the constraint, objective function and free variables. As the tooth root failure and/ or breakage is the major gear design problem, the constraint was determined as bending fatigue failure criteria whereas the objective function was minimizing the mass of gear based on the bending strength. Ashby charts were used to obtain suitable materials and material index values were ranked by using CES Selector tool. After determining the suitable materials, a number of gear designs were carried out. Then the results were compared to each other according to their module and face width values.

\section{METHODOLOGY}

The different type of material selection methods are available in the literature such as decision matrix, pugh method, analytic hierarchy process (AHP), and etc. [17]. When the effectiveness of the methods are compared, it is seen that Ashby methodology better than the others. Because the above mentioned evaluation methods need experience and judgement in contrast to Ashby's method. Engineer has to determine correct weight factors to evaluate the candidate materials. On the other hand, just using required design formula is sufficient to determine optimum material for the designed object in the Ashby material selection strategy. In addition, material index of the each material is accurate and there is no doubt since the determination of the material index is a parametric study in the Ashby method.

\subsection{Application of Ashby Material Selection Method to Spur Gear Design}

Firstly, objective function (what is to be maximized or minimized?) then constraints (design requirements that must be met: stiffness, strength, etc.) and free variables (Which are the unconstrained variables of the problem?) must be determined to perform the Ashby's method [15].

A flow chart was given in Figure 1 to facilitate the understanding of the method.

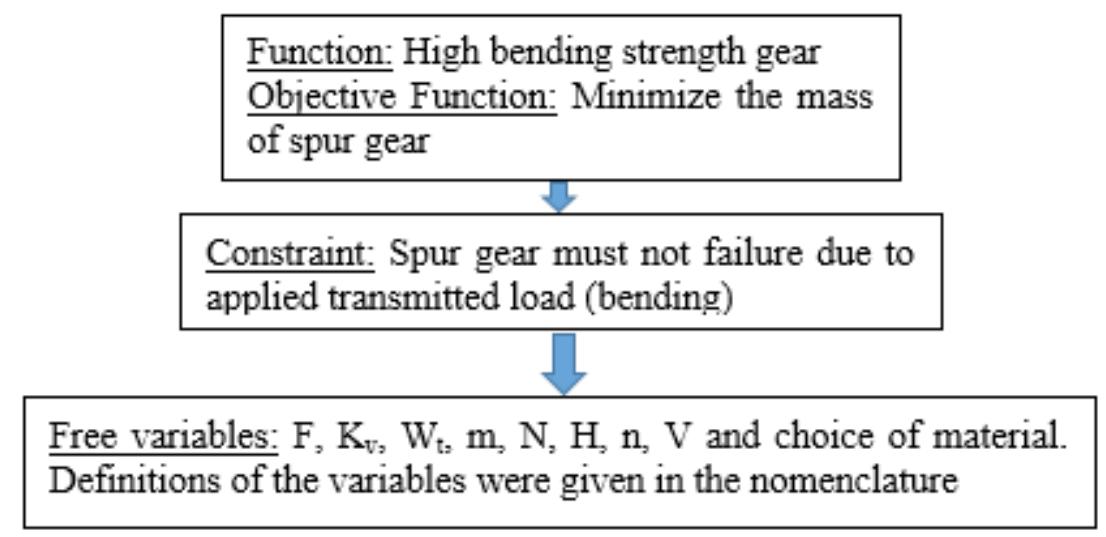

Figure 1: Ashby Material Selection Strategy

After the simultaneously evaluating the objective function, constraints and free variables, material index can be found.

According to the Ashby method, the performance of a structural element depends the functional requirements, the geometry, and the properties of the material of the structure [15]. The performance (P) of the element is defined by following equation;

$$
P=\left[\left(\begin{array}{c}
\text { Functional } \\
\text { Requirements, F }
\end{array}\right),\left(\begin{array}{c}
\text { Geometric } \\
\text { parameters, G }
\end{array}\right),\left(\begin{array}{c}
\text { Material } \\
\text { Properties, M }
\end{array}\right)\right]
$$

Where $\mathrm{P}$ is the performance of a structural element that describes the performance of the component such as its mass, volume, cost, or life. Optimum design is the selection of the material and geometry that maximize or minimize P, according to its desirability [15].

\subsubsection{Objective Function for the Spur Gear Design}

We first seek an equation describing the quantity to be minimized. Here it is the mass $\mathrm{m}$ of the gear. Mass of a spur gear 
can be calculated approximately as mass of a cylinder whose radius and height equals to half of the pitch diameter and face width of the spur gear respectively [18]. So mass (M) of one spur gear is given by:

$$
M=\pi r^{2} F \rho
$$

Replacing the terms by:

$$
\begin{aligned}
& 3 \pi \mathrm{m} \leq \mathrm{F} \leq 5 \pi \mathrm{m}=\mathrm{F}=\mathrm{C}_{1} \pi \mathrm{m} \text { where } 3 \leq \mathrm{C}_{1} \leq 5 \\
& \mathrm{~d}=\mathrm{mN}
\end{aligned}
$$

Mass equation (Eq. 2) becomes:

$$
\mathrm{M}=\mathrm{C}_{1} \frac{\pi^{2}}{4} \mathrm{~N}^{2} \mathrm{~m}^{3} \rho
$$

\subsubsection{Constraint}

Spur gear either is designed for bending or surface strength failure criteria. If the wearing of the spur gear tooth surface is important then the spur gear must be designed due to pitting resistance otherwise it must be designed based on bending fatigue failure. In this work the spur gear were designed against the bending stress failure criteria because it is mostly the primary requirement in the industry.

So the bending stress on the spur gear tooth must be equal or smaller than the fatigue strength (S) of spur gear material.

$\sigma \leq S$

Spur gear must support transmitted load $\left(\mathrm{W}_{\mathrm{t}}\right)$ without failure. Therefore, Lewis bending stress equation (Eq. 7) is used in this work instead of AGMA bending stress equation since all parameters are free variable and AGMA equation is too complex to determine material index. Lewis approach relies on the force application on the top of the tooth as shown in Figure 2.

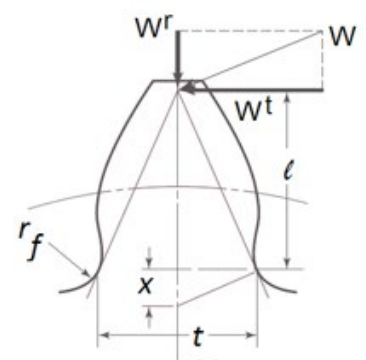

Figure 2: Position of the applied forces on gear tooth due to Lewis approach [19]

$$
\sigma=\frac{\mathrm{K}_{\mathrm{v}} \mathrm{W}_{\mathrm{t}}}{\mathrm{FmY}}
$$

Replacing the terms by

$$
\begin{aligned}
& \mathrm{V}=\frac{\pi \mathrm{dn}}{60} \\
& \mathrm{~d}=\mathrm{mN} \\
& \mathrm{K}_{\mathrm{v}}=\frac{6.1+\mathrm{V}}{6.1} \\
& \mathrm{~W}_{\mathrm{t}}=\frac{19098,593 \mathrm{H}}{\mathrm{mNn}}
\end{aligned}
$$

Eq. (7) becomes:

$$
\sigma=\frac{19098,593 \mathrm{H}+52,2 \pi \mathrm{NnHm}}{\mathrm{C}_{1} \pi \mathrm{m}^{3} \mathrm{NnY}}
$$

\subsection{Determination of Material Index}

Module (m) in Eq. (5) must be determined as a function of the strength (S) to find material index. Therefore, firstly, Eq. (12) was simplified by replacing 


$$
\begin{aligned}
& \mathrm{C}_{2}=19098,593 \mathrm{H} \\
& \mathrm{C}_{3}=\mathrm{C}_{1} \pi \mathrm{NnY} \\
& \mathrm{C}_{4}=52,2 \pi \mathrm{NnH}
\end{aligned}
$$

and transformed to:

$$
\sigma=\frac{\mathrm{C}_{2}+\left(\mathrm{C}_{4} \mathrm{~m}\right)}{\mathrm{C}_{3} \mathrm{~m}^{3}}
$$

To find module (m) as a function of strength (S), Eq. (6) must be solved by inserting Eq. (16) to Eq. (6). Due to complexity of the equation, computer aided mathematic program may be used to find solution [20]. Since the obtained equation is third order, there will be three roots for the equation. Therefore, all of the three roots of the equation is given as follows:

$$
\begin{aligned}
& m_{1}=\frac{(1+i \sqrt{3}) \mathrm{c}_{4}}{2^{2 / 3} 3^{1 / 3}\left(-9 \mathrm{~S}^{2} \mathrm{c}_{2} \mathrm{c}_{3}^{2}+\sqrt{3} \sqrt{27 \mathrm{~S}^{4} \mathrm{c}_{2}^{2} \mathrm{c}_{3}^{4}-4 \mathrm{~S}^{3} \mathrm{c}_{3}^{3} \mathrm{c}_{4}^{3}}\right)^{1 / 3}}+\frac{(1-\mathrm{i} \sqrt{3})\left(-9 \mathrm{~S}^{2} \mathrm{c}_{2} \mathrm{c}_{3}^{2}+\sqrt{3} \sqrt{\left.27 \mathrm{~S}^{4} \mathrm{c}_{2}^{2} \mathrm{c}_{3}^{4}-4 \mathrm{~S}^{3} \mathrm{c}_{3}^{3} \mathrm{c}_{4}^{3}\right)^{1 / 3}}\right.}{22^{1 / 3} 3^{2 / 3} \mathrm{Sc}_{3}}
\end{aligned}
$$

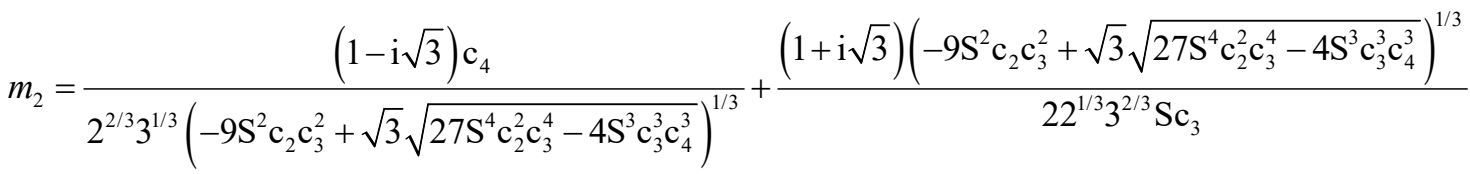

$$
\begin{aligned}
& m_{3}=-\frac{\left(\frac{2}{3}\right)^{1 / 3} c_{4}}{\left(-9 S^{2} c_{2} c_{3}^{2}+\sqrt{3} \sqrt{27 S^{4} c_{2}^{2} c_{3}^{4}-4 S^{3} c_{3}^{3} c_{4}^{3}}\right)^{1 / 3}}-\frac{\left(-9 S^{2} c_{2} c_{3}^{2}+\sqrt{3} \sqrt{\left.27 S^{4} c_{2}^{2} c_{3}^{4}-4 S^{3} c_{3}^{3} c_{4}^{3}\right)^{1 / 3}}\right.}{2^{1 / 3} 3^{2 / 3} \mathrm{Sc}_{3}}
\end{aligned}
$$

Since the $\mathrm{m}_{1}$ and $\mathrm{m}_{2}$ are imaginary roots, only the $\mathrm{m}_{3}$ was considered as the real root of the equation. After subjecting the root $\mathrm{m}_{3}$ into Eq. (5), the maximum power of $S$ on the expression was found as minus one. That means $\mathrm{m}^{3}$ in Eq. (5) equals to $S^{-1}$ as a function of strength.

Therefore, performance of a structural element $(\mathrm{P})$ for the spur gear design based on bending fatigue failure is found as:

$$
P(\text { Performance })=\operatorname{Mass}(M)=\left(\mathrm{C}_{1} \frac{\pi^{2}}{4}\right)\left(\mathrm{N}^{2}\right)\left(\frac{\rho}{\mathrm{S}}\right)
$$

The material index is $\left(\frac{\mathrm{S}}{\rho}\right)$. If we maximize the material index $\left(\frac{\mathrm{S}}{\rho}\right)$, we can minimize the result $(\mathrm{M})$.

When the performance equation is investigated, it is seen that there are two important material properties that minimize the mass. One of them is fatigue strength of the gear material that is directly related to ultimate tensile strength $\left(S_{\text {ut }}\right)$ of the material and the other is density of the gear material. Therefore, strength must be high while density is low to minimize the mass of a spur gear. That is to say $\mathrm{S} /$ must be high to select optimum gear material based on the bending fatigue failure.

\subsection{Application of Ashby Charts}

Ashby charts include all material families called as metals, ceramics, polymers, elastomers, hybrids. Figure 3 shows the location of all the materials in fatigue strength vs. density graphic. 


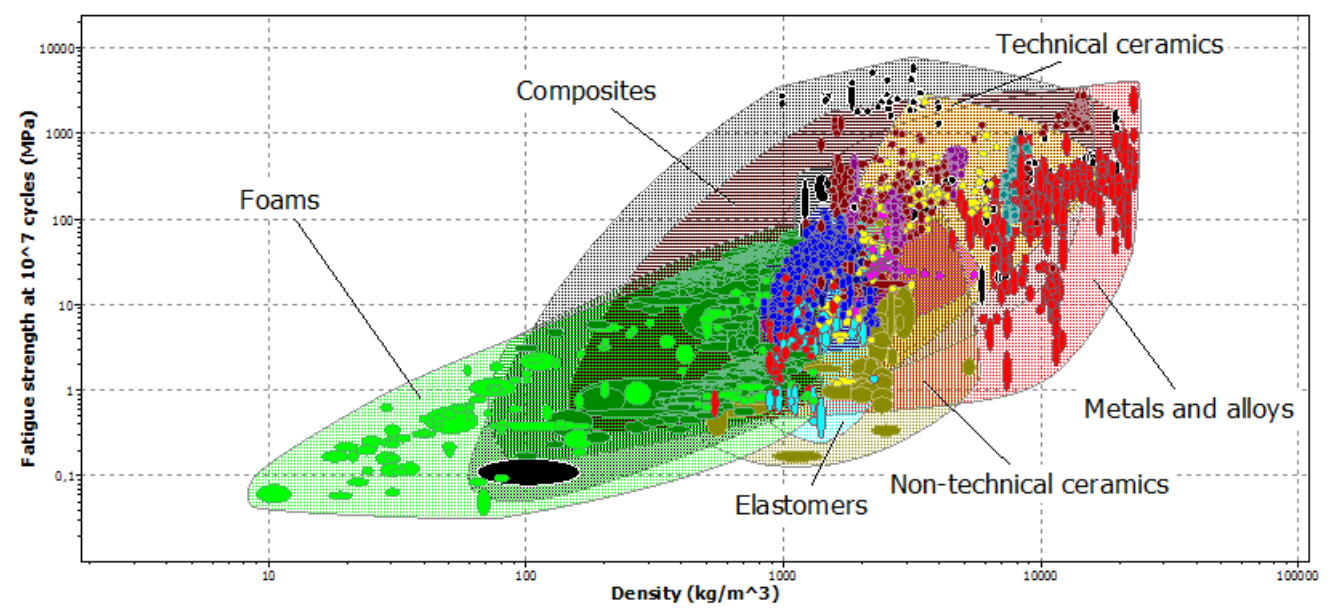

Figure 3: Material families in fatigue strength vs. density graphic [15]

As it is also reported in the literature [14], the gear materials are commonly selected from metals for industrial engineering applications. In Figure 4, only the metals are shown. The slope line in the figure was obtained from the material index, $\mathrm{S} / \rho$, and it means that the materials on the line have the same material index value. The slope line separates the eliminated materials (grey locations). And the materials above the line can be a candidate considering the material index. In this study, some of the candidate materials for spur gear design were labelled as seen in Figure 4.

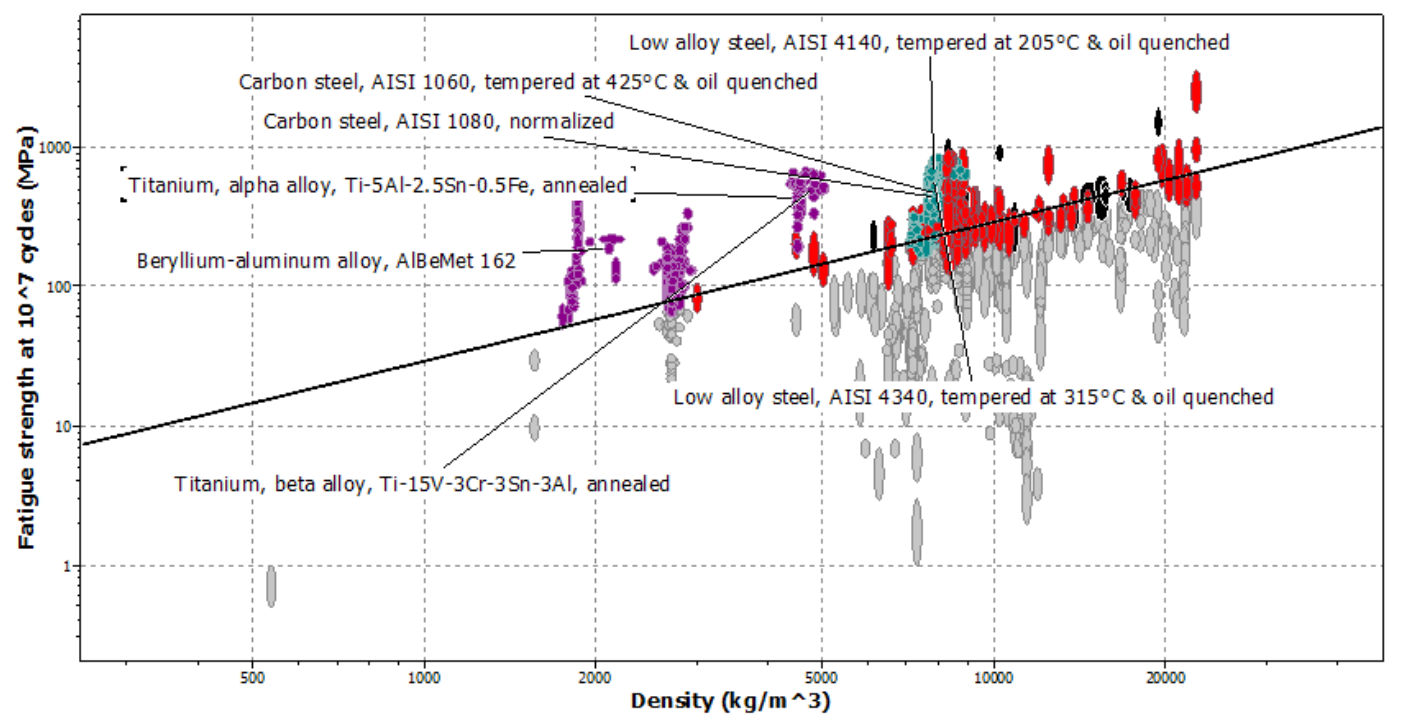

Figure 4: Candidate materials for high strength and low weight spur gear design [16]

The material index values according to the selected candidate materials were ranked and given in Table 1 . The properties of the selected candidate materials were listed in Table 2.

Table 1 Material index values of the selected candidate materials

\begin{tabular}{|c|c|c|}
\hline No & Material & Index Value \\
\hline 1 & Titanium, beta alloy, Ti-15V-3Cr-3Sn-3Al, annealed & 0,105 \\
\hline 2 & Titanium, alpha alloy, Ti-5Al-2.5Sn-0.5Fe, annealed & 0,0958 \\
\hline 3 & Beryllium-aluminium alloy, AlBeMet 162 & 0,0901 \\
\hline 4 & AISI 4140 tempered @205C \& oil quenched & 0,0811 \\
\hline 5 & AISI 4340 tempered @315C \& oil quenched & 0,0808 \\
\hline 6 & AISI 4140, tempered at 315 $\mathrm{C} \&$ oil quenched & 0,0738 \\
\hline 7 & AISI 4340, tempered at 425 $\mathrm{C} \&$ oil quenched & 0,0711 \\
\hline 8 & AISI 1080 tempered @205C \& oil quenched & 0,0656 \\
\hline 9 & AISI 1080 tempered @425C \& oil quenched & 0,0649 \\
\hline 10 & AISI 1060, tempered at 425 C \& oil quenched & 0,0572 \\
\hline 11 & AISI 4140, normalized & 0,0551 \\
\hline 12 & AISI 1080, normalized & 0,0547 \\
\hline
\end{tabular}


Table 2 Properties of the selected candidate materials

\begin{tabular}{|c|c|c|c|c|c|c|}
\hline No. & $\begin{array}{c}\text { Density, } \\
\mathbf{k g} / \mathbf{m}^{\mathbf{3}}\end{array}$ & $\begin{array}{c}\text { Young Modu- } \\
\text { lus, GPa }\end{array}$ & $\begin{array}{c}\text { Yield Stren- } \\
\text { gth, MPa }\end{array}$ & $\begin{array}{c}\text { Tensile Stren- } \\
\text { gth, MPa }\end{array}$ & $\begin{array}{c}\text { Hardness, } \\
\text { HV }\end{array}$ & $\begin{array}{c}\text { Poisson's } \\
\text { ratio }\end{array}$ \\
\hline 1 & 4750 & 108 & 749 & 770 & 225 & 0,35 \\
\hline 2 & 4460 & 107 & 758 & 793 & 344 & 0,32 \\
\hline 3 & 2070 & 179 & 193 & 262 & 115 & 0,165 \\
\hline 4 & 7800 & 208 & 1480 & 1600 & 455 & 0,285 \\
\hline 5 & 7800 & 205 & 1430 & 1550 & 435 & 0,285 \\
\hline 6 & 7800 & 208 & 1290 & 1400 & 400 & 0,285 \\
\hline 7 & 7800 & 205 & 1230 & 1320 & 385 & 0,285 \\
\hline 8 & 7800 & 200 & 880 & 1180 & 360 & 0,285 \\
\hline 9 & 7800 & 200 & 855 & 1160 & 350 & 0,285 \\
\hline 10 & 7800 & 208 & 685 & 965 & 280 & 0,285 \\
\hline 11 & 7800 & 208 & 595 & 915 & 275 & 0,285 \\
\hline 12 & 7800 & 200 & 470 & 905 & 270 & 0,285 \\
\hline
\end{tabular}

\section{RESULTS AND DISCUSSIONS}

12 different materials, which can be suitable for the design of spur gears, were determined from the Ashby charts. In spur gear design, an iterative process is carried out. Firstly, a starting module is estimated and it is iterated until the face width (F) obtained in an acceptable range [2]. The Lewis formula given in section 2.1 was applied to determine $\mathrm{m}$ and $\mathrm{F}$ values. A simple design problem was identified to check the material index of the materials. Table 3 gives the requirement of the design problem. Based on the requirements, the design of gears were performed. Table 4 shows the $\mathrm{m}$ and $\mathrm{F}$ results considering the selected materials. In the last column of the table the weight of the gears are presented.

Table 3 Requirements of the spur gear design problem

\begin{tabular}{|c|c|}
\hline Parameter & Corresponding value \\
\hline Pressure angle, $\varnothing$ & $20^{\circ}$ \\
\hline Gear tooth geometry & Standard, interference free, involute spur, full depth teeth \\
\hline Input speed of power source & $1200 \mathrm{rpm}$ \\
\hline Transmitted power & $10 \mathrm{~kW}$ \\
\hline Output shaft speed & $400 \mathrm{rpm}$ \\
\hline Number of life cycles & $10^{7}$ \\
\hline Materials & Selected from Ashby chart \\
\hline Design criteria & Based on bending fatigue \\
\hline
\end{tabular}

Table 4 Module, face width and weight results of the spur gears

\begin{tabular}{|c|c|c|c|}
\hline Material & Module, $\mathrm{mm}$ & Face width, mm & Weight, kg \\
\hline Titanium, beta alloy, Ti-15V-3Cr-3Sn-3Al, annealed & 3,5 & 45,46 & 8,90 \\
\hline Titanium, alpha alloy, Ti-5Al-2.5Sn-0.5Fe, annealed & 3 & 46,4 & 7,31 \\
\hline Beryllium-aluminum alloy, AlBeMet 162 & 3,75 & 56,04 & 5,12 \\
\hline AISI 4140 tempered at $205^{\circ} \mathrm{C}$ and oil quenched & 3 & 37,92 & 10,45 \\
\hline AISI 4340 tempered at $315^{\circ} \mathrm{C}$ and oil quenched & 3 & 39,21 & 10,81 \\
\hline AISI 4140 , tempered at $315^{\circ} \mathrm{C}$ and oil quenched & 3 & 41,74 & 11,51 \\
\hline AISI 4340 , tempered at $425^{\circ} \mathrm{C}$ and oil quenched & 3 & 42,88 & 11,82 \\
\hline AISI 1080 tempered at $205^{\circ} \mathrm{C}$ and oil quenched & 3 & 44,98 & 12,40 \\
\hline AISI 1080 tempered at $425^{\circ} \mathrm{C}$ and oil quenched & 3 & 45,82 & 12,63 \\
\hline AISI 1060 , tempered at $425^{\circ} \mathrm{C}$ and oil quenched & 3,25 & 45,74 & 13,66 \\
\hline AISI 4140, normalized & 3,25 & 46,3 & 13,83 \\
\hline AISI 1080, normalized & 3,25 & 46,99 & 14,03 \\
\hline
\end{tabular}

As it seen from Table 4 carbon steels and low alloy steels provide relatively high weight although they are the most commonly used gear materials. The lightest steel was determined as AISI 4140 tempered at $205^{\circ} \mathrm{C}$ and oil quenched $(10,45 \mathrm{~kg})$. However, the heaviest recommended material (Titanium beta alloy, 8,90 kg) even was found approximately $15 \%$ lighter than the lightest steel. And the weight reduction for other recommended materials that are titanium alpha alloy and beryllium-aluminum alloy compared to the lightest steel was approximately $30 \%$ and 
$51 \%$, respectively. When the heaviest steel (AISI 1080, normalized, $14,03 \mathrm{~kg}$ ) was considered, the weight gain can be $63 \%$.

\section{CONCLUSION}

Application of an advanced material selection technique such as the Ashby method is found to be very useful for optimization related engineering problems since the structural optimization is always not sufficient and mostly depends on approximate material selection. Especially, in weight critical applications such as in aerospace or medical fields, a proper lightweight material selection with high strength is become essential for optimization related design problems. In this study, the Ashby method was used to investigate lightweight, high strength materials for spur gear design. Material index values of the materials based on the bending fatigue strength were determined and ranked. The ranking was also in a good agreement with spur gear design results. Therefore, new generation materials such as titanium alloys or beryllium alloys provided approximately $36 \%$ to $63 \%$ weight reduction compared to conventional gear materials.

\section{NOMENCLATURE}

$\mathrm{N}=$ number of teeth

$\mathrm{d}=$ pitch diameter, $\mathrm{mm}$

$\mathrm{m}=$ module, $\mathrm{mm}$

$\mathrm{S}=$ Fatigue strength of gear material, MPa

$=$ density, $\mathrm{kg} / \mathrm{m}^{3}$

$\mathrm{F}=$ face width, $\mathrm{mm}$

$\mathrm{W}_{\mathrm{t}}=$ Transmitted load, $\mathrm{kN}$

$\mathrm{n}=$ speed, rev/min

$\mathrm{H}=$ power, $\mathrm{kW}$

$\mathrm{K}_{\mathrm{v}}=$ dynamic factor

$\mathrm{Y}=$ Lewis form factor

$\sigma=$ bending stress, $\mathrm{MPa}$

$\mathrm{C}_{1}, \mathrm{C}_{2}, \mathrm{C}_{3}$ and $\mathrm{C}_{4}=$ coefficients

$\mathrm{V}=$ pitch-line velocity, $\mathrm{m} / \mathrm{s}$

\section{DISCLAIMER}

Certain commercial software products are identified in this paper. These products were used only for demonstration purposes. This use does not imply approval or endorsement by Çukurova University \& Adana Science and Technology University, nor does it imply that these products are necessarily the best for the purpose.

\section{REFERENCES}

[1] Juvinall R.C., Marshek K.M., 2011. Fundamentals of Machine Component Design. Wiley 5th Edition, 928 pages.

[2] Budynas R.G. and Nisbett J.K., 2011. Shigley's Mechanical Engineering Design. Ninth Edition, McGraw-Hill, 1120 pages.

[3] Li S., 2007. Finite Element Analyses For Contact Strength and Bending Strength of A Pair of Spur Gears With Machining Errors, Assembly Errors and Tooth Modifications. Mechanism and Machine Theory 42, 88-114.

[4] Pedersen N.L., Raju P.R., Sreenivasulu V., Rao P.D. and Kiran C.U., 2010. Improving Bending Stress in Spur Gears Using Asymmetric Gears and Shape Optimization. Mechanism and Machine Theory 45, pp.1707-1720.

[5] Sankar S. and Nataraj M., 2011. Profile Modification - A Design Approach for Increasing the Tooth Strength in Spur Gear. The International Journal of Advanced Manufacturing Technology, 55:1-10.

[6] Geren N. and Baysal M.M., 2000. Expert System Development for Spur Gear Design. 9. International Conference on Machine Design and Production.

[7] Mendi F., Başkal T., Boran K. and Boran F.E., 2010. Optimization of Module, Shaft Diameter and Rolling Bearing for Spur Gear through Genetic Algorithm. Expert Systems with Applications, 37, 8058-8064.

[8] Parthiban A., Raju P.R., Sreenivasulu V., Rao P.D. and Kiran C.U., 2013. Profile Modification for Increasing the Tooth Strength in Spur Gear using CAD \& CAE. International Journal of Innovations in Engineering and Technology, Vol.2, Issue 1, pp. 231-241. 
[9] Gupta B., Choubey A. and Varde G.V., 2012. Contact Stress Analysis of Spur Gear. International Journal of Engineering Research \& Technology (IJERT) Vol. 1 Issue 4, 7 pages.

[10] Jebur A.K., Khan I.A. and Nath Y., 2011. Numerical and Experimental Dynamic Contact of Rotating Spur Gear. Modern Applied Science, Vol. 5, No. 2, pp. 254-263.

[11] Tiwari S.K. and Joshi U.K., 2012, Stress Analysis of Mating Involute Spur Gear teeth. International Journal of Engineering Research and Technology, Volume 1, Issue 9.

[12] Marjanovic N., Isailovic B., Marjanovic V., Milojevic Z., Blagojevic M. and Bojic M., 2012. A Practical Approach to the Optimization of Gear Trains with Spur Gears, Mechanism and Machine Theory, 53, pp. 1-16.

[13] Golabi S., Fesharaki J.J. and Yazdipoor M., 2014. Gear Train Optimization Based on Minimum Volume/Weight Design, Mechanism and Machine Theory, 73, pp. 197-217.

[14] Stephen P. Radzevich. 2012. Dudley’s Handbook of Practical Gear Design and Manufacture, CRC Press.

[15] Michael F. Ashby, 2011. Materials Selection in Mechanical Design, $4^{\text {th }}$ edition, Elsevier Ltd.

[16] CES Selector 2016. www.grantadesign.com

[17] Dieter and Schmidt, 2009. Engineering Design, $4^{\text {th }}$ edition. McGraw Hill Company.

[18] Roos F. 2004. Relations between Size and Gear Ratio in Spur and Planetary Gear Trains, Technical Report, Royal Institute of Technology, Stockholm.

[19] Geren N., 2017. Makina Mühendisliğine Giriş. Birinci Baskı, published in Turkish, İstanbul papatya bilim 667 pages.

[20] https://www.wolfram.com/mathematica/ 